\title{
Serum Interleukin-6 Level Raise Up In Time With Muscle Soreness at 24 Hours Recovery From Vigorous Exercise: Does It Correlate?
}

\author{
Selly Omega Dila Teju ${ }^{\mathrm{a}}$, Bambang Purwanto ${ }^{\mathrm{b}}$, Novadri Ayubic* \\ *bpaifo@gmail.com \\ ${ }^{a}$ Master Program of Sport Health Science, Faculty of Medicine University Airlangga 60131, Surabaya, East Java, Indonesia \\ ${ }^{b}$ Department of Medical Physiology and Biochemistry, Faculty of Medicine University Airlangga 60131, Surabaya, East Java, Indonesia \\ ${ }^{c}$ Doctoral Program of Sport Science, University Negeri Surabaya, East Java, Indonesia
}

\begin{abstract}
Background : Muscle soreness or muscle pain occurs after long-term physical activity or after unusual exercise. Some explains it due to pro inflammatory cytokines secreted during and after exercise. Interleukin- 6 and tumor necrotic factor alpha were two cytokines believed as promoting factor of muscle soreness. Until now, it was still unclear whether interleukin- 6 or tumour necrotic factor alpha that correlate with the soreness found at 24 hours recovery from vigorous exercise.

Purpose : This study was aimed to analyse the level of interleukin-6 and tumour necrotic factor alpha by time of 6- and 24-hour recovery from exercise. Method/Material: Correlation study research method with a cross-sectional research design. The subject of this study were twenty voluntary trained, healthy male, aged 20-30 years old with normal body mass index was randomly registered in this study. Subjects was grouped in vigorous exercised group and moderate exercised group as control. The blood was obtained from the subjects at 6 and 24 hours recovery post exercise for interleukin-6 and tumor necrotic factor alpha level measurement.

Result : Was shown raised of pain intensity of muscle soreness and interleukin-6 level but not tumor necrotic alpha level. The interleukin- 6 level correlated to the pain intensity of muscle soreness at 24 hours post exercise $(\mathrm{P}<0,05)$.
\end{abstract}

\section{Introduction}

Muscle soreness often found during recovery post vigorous exercise. Some explains it due to pro inflammatory cytokines secreted during and after exercise. Interleukin- 6 and tumor necrotic factor alpha were two cytokines believed as promoting factor of muscle soreness (Cornish \& Johnson, 2014; Castellani et al., 2015). Until now, it was still unclear whether interleukin-6 or tumor necrotic factor alpha that correlate with the soreness found at 24 hours recovery from vigorous exercise.

Muscle and immunocompetence cells were able to secrete pro inflammatory cytokines as response of physical stress during exercise (Choy \& Rose-John, 2017). Both were identically undifferent in molecular weight and structure but its effects were different. Interleukin-6 secreted from muscle had metabolic effect on glucose and cholesterol uptake during exercise and peaked at 6 hours recovery from exercise. After 24 hours 
recovery from exercise the interleukin- 6 level reclimbed for the second peak. There wasn't any study explain more about the interleukin-6 reclimb (Hennigar et al., 2017).

This study was aimed to analyse the level of interleukin- 6 and tumour necrotic factor alpha by time of 6- and 24-hour recovery from exercise. We also analysed the visual analogue scale of muscle soreness at 6and 24-hour recovery from exercise. The corelation test was performed statistically between cytokines level and visual analogue scale of muscle soreness correlation.

\section{Method}

This study uses correlation study research method with a cross-sectional research design. The subjects were 20 voluntary trained, healthy male, aged 20-30 years old with normal body mass index. They were grouped in to vigorous exercise and control group. The vigorous exercise group performed squad and leg press with exercise intensity of $80-90 \%$ of maximum load, carried out four sets, ten repetitions, and recovery between sets of 60 seconds. The control performed squad and leg press without any exercise load at carried out four sets, ten repetitions, and recovery between sets of 60 seconds. Subjects were then collected their blood from mediana cubitii vein for next processing procedure to get serum at the same time with subjects fill the visual analogue scale of muscle soreness. It repeated twice at 6 and 24 hours recovery from exercise.

The blood serum was measured for interleukin-6 and tumour necrotic factor alpha level using ELISA Method. The ELISA Kit was obtained from Elabscience Human IL-6 Kit (Interluekin-6) catalog No E. EL.HO.102 and Human TNF-alpha Kit catalogue No E. EL.HO.109. Visual analogue scale was used to determine the level of muscle soreness at 6 and 24 hours recovery from exercise.

\section{Result}

Subjects were characterized as male, age ranged of 20-23 years of old with normal body mass index and blood pressure (BP). All characteristics were determined pre-exercise protocol. The characteristics were as follows.

Table 1. The characteristics of Subjects

\begin{tabular}{lrr}
\hline Characteristics & \multicolumn{2}{c}{ Group of exercise } \\
\cline { 2 - 3 } & \multicolumn{2}{c}{ Control } \\
\hline Age (years) & $23.10 \pm 6.13$ & $24.30 \pm 8.21$ \\
Weight $(\mathrm{kg})$ & $64.00 \pm 7.48$ & $60.45 \pm 6.90$ \\
Body Mass Index/ BMI $\left(\mathrm{kg} / \mathrm{cm}^{2}\right)$ & $22.94 \pm 2.46$ & $21.72 \pm 2.69$ \\
Systolic BP $(\mathrm{mmHg})$ & $107.00 \pm 10.59$ & $117.00 \pm 6.32$ \\
Diastolic BP $(\mathrm{mmHg})$ & $72.00 \pm 3.75$ & $79.00 \pm 8.75$ \\
\hline
\end{tabular}

Post exercise, each subject was determined it cytokines serum level and visual analogue scale of muscle soreness at 6 hours and 24 hours recovery time. Data were described as mean \pm standard deviation as seen on table 2 and 3. 
Table 2. Correlation Between Serum IL-6 With VAS Score of Muscle Soreness In Time

\begin{tabular}{|c|c|c|c|c|c|c|}
\hline \multirow[b]{2}{*}{ Group } & \multirow[b]{2}{*}{ Variable } & \multicolumn{2}{|c|}{ Recovery } & \multirow{2}{*}{$\begin{array}{c}\text { Pair t test } \\
\mathrm{p}(\mathrm{sig})\end{array}$} & \multicolumn{2}{|c|}{ Rank Spearman } \\
\hline & & 6 hours & 24 hours & & $\mathrm{p}(\operatorname{sig})$ & $\begin{array}{l}\text { Correlation } \\
\text { Coefficient }\end{array}$ \\
\hline \multirow[t]{2}{*}{ Control } & IL-6 & $8.53 \pm 3.99$ & $8.82 \pm 5.87$ & 0.47 & \multirow{2}{*}{0.99} & \multirow{2}{*}{0.001} \\
\hline & VAS & $5.90 \pm 0.87$ & $5.50 \pm 0.70$ & 0.27 & & \\
\hline \multirow[t]{2}{*}{ Vigorous } & IL-6 & $9.97 \pm 2.84$ & $11.91 \pm 3.53$ & $0.03 *$ & \multirow[b]{2}{*}{$0.03 *$} & \multirow[b]{2}{*}{0.483} \\
\hline & VAS & $3.60 \pm 1.83$ & $6.00 \pm 1.24$ & $0.001^{*}$ & & \\
\hline
\end{tabular}

Post vigorous exercise, the interleukin-6 serum level and soreness score of VAS rasied higher during 6 untill 24 hours recovery time. It was absent on control which interleukin-6 and soreness score of VAS was undiffer. Spearman test result confirmed a moderate correlation between interleukin-6 level of serum with soreness score of VAS post vigorous exercise, but not in control.

Post vigorous exercise, the tumour necrotic factor alpha serum level was in steady during 6 to 24 hours recovery time. It differed to interleukin-6 serum level and VAS soreness score which consistaantly higher during 6 to 24 hours recovery time. The soreness score of VAS did not correlate to tumour necrotic factor alpha, both in control and vigorous exercise groups.

Table 3. Correlation Between Serum TNF-a With VAS Score of Muscle Soreness In Time

\begin{tabular}{|c|c|c|c|c|c|c|}
\hline \multirow{2}{*}{ Group } & \multirow{2}{*}{ Variable } & \multicolumn{2}{|c|}{ Recovery } & \multirow{2}{*}{$\begin{array}{c}\text { Pair t test } \\
\text { p (sig) }\end{array}$} & \multicolumn{2}{|c|}{ Rank Spearman } \\
\hline & & 6 hours & 24 hours & & $\mathrm{p}$ (sig) & Correlation Coefficient \\
\hline \multirow[t]{2}{*}{ Control } & TNF-a & $4.70 \pm 1.54$ & $4.61 \pm 2.53$ & 0.86 & \multirow{2}{*}{0.97} & \multirow{2}{*}{0.001} \\
\hline & VAS & $5.90 \pm 0.87$ & $5.50 \pm 0.70$ & 0.27 & & \\
\hline \multirow[t]{2}{*}{ Vigorous } & TNF-a & $4.50 \pm 1.03$ & $5.04 \pm 2.66$ & 0.18 & \multirow{2}{*}{0.35} & \multirow{2}{*}{0.06} \\
\hline & VAS & $3.60 \pm 1.83$ & $6.00 \pm 1.24$ & $0.001 *$ & & \\
\hline
\end{tabular}

\section{Discussion}

Previously, both interleukin-6 and tumor necrotic alpha were believed as cytokines who responsible to muscle soreness 24 hours recovery time after vigorous exercise. Both induced inflammation and massive restoration of damaged muscle. Non steroid anti inflammatory drugs reduced inflammation in time with interleukin-6 and tumor necrotic factor alpha serum level fallen. Non steroid anti inflammatory drugs widely used to heal muscle soreness, ultimately among untrained (Bazgir et al., 2019 and Carbone et al., 2005).

Our findings reconfirmed that only interleukin- 6 but not tumour necrotic factor level who correlated to muscle soreness during 6 untill 24 hours recovery time post vigorous exercise. Previously, a systematic review study of Suzuki et al (2002) found significantly raised of interleukin-6 level in time with muscle soreness among subjects who did exhaustive exercise. This was not followed by TNF alpha and interleukin-1 level, as traditional pro-inflammatory cytokines.

Different results were found by Pereira et al (2015) and Chaffin et al (2011) studies. The interleukin-6 level was not vary after exercise by time in elderly and reproductive females. The exercise protocols were handgrip exercise among elderly and 75 min high intensity interval running among reproductive female. Different subjects and protocols explained a dispute result of our study.

Exercise was measurable and controlled stressor for muscle and other organs during physically active. Exercise induced physical stress, metabolic stress and oxidative stress. Muscle secreted interleukin- 6 as quick response to survive under these stress circumtances. Interleukin- 6 was one of myokines which secreted during and after exercise. It was available only in short period then excreted and found in the urine. Interleukin- 6 level increased significantly an hours after exercise untill reach it peak at 6 hours after (Soares et al., 2020 and Morettini et al., 2017).

Interleukin-6 increase muscle glucose metabolism and uptake via insulin independent pathway. The 
enhanced of glucose upatke and metabolism is coincident with an increase of adenosine monophsophate kinase (AMPK) phosphorylation. The adenosine monophsophate kinase (AMPK) phosphorylation plays a pivot role in glucose uptake and metabolsim It beneficial to restore ATP as fuel of energy for muscle during and after exercise (Glund et al., 2007 and Lehrskov et al., 2019).

Interleukin-6 also increase lipid metabolism and cholesterol uptake during and after exercise (Lehrskov et al., 2019). Previous study, we found moderate gymnastic exercise increased interleukin-6 level in time with total cholesterol level fallen among sedentary females (Pratiwi et al., 2019). Cholesterol was used to repair membrane damage because of lipid peroxidation by radical oxidant. Lipid peroxidation induces membrane liquidity, alters the mozaic pattern and increases the membrane permeability to extracellular substances. This process leads to necrosis, swelling and inflammation (Feraco et al., 2021).

Myo-interleukin-6 inhibited the muscle damage process in early stage of 6 hours recovery post exercise. If it succed then we expected the process did not continue to necrosis and inflammation. On the contrary, there would be an augmented mechanism to resolve the damage massively. Immunocompetence cells secreted interleukin-6 at 12 hours until peaked at 24 hours recovery post exercise (Scheller et al., 2011 and Huldani et al., 2020).

\section{Conclusion}

Our findings confirmed this hypothesis. The intensity of exercise did not vary the interleukin- 6 level. The vigourous but not moderate exercise (shown in control) induced higher level of interleukin-6 at 24 hours than at 6 hours recovery post exercise. The pain intensity of muscle soreness was also found more at 24 hours among the vigorous exercised subjects. The correlation test resulted a moderate correlation between interleukin-6 level and the pain intensity of muscle soreness at 24 hours recovery post exercise. The test also confirmed that the TNF alpha level did not correlate to the pain intensity of muscle soreness in the same time.

\section{Acknowledgements}

The authors are very thankful to the Faculty of Medicine, Universitas Airlangga.

\section{References}

Bazgir, B., Delpasand, A., \& Shirvani, H. 2019. Serum levels of interleukin-6 (IL-6), IL-10, and lactate in response to combat physical fitness test. Sport Sciences for Health, 6(March).

Carbone, M., Ly, B. H., Dodson, R. F., Pagano, I., Morris, P. T., Dogan, U. A., Gazdar, A. F., Pass, H. I. and Yang, H. 2012. 'Malignant mesothelioma: Facts, Myths, and Hypotheses', Journal of Cellular Physiology. doi: 10.1002/jcp.22724. Chu, A. J. (2005) 'Tissue factor mediates inflammation', Archives of Biochemistry and Biophysics.

Castellani, L., Perry, C. G. R., MacPherson, R. E. K., Root-McCaig, J., Huber, J. S., Arkell, A. M., Simpson, J. A., \& Wright, D. C. 2015. Exercise-mediated IL-6 signaling occurs independent of inflammation and is amplified by training in mouse adipose tissue. Journal of Applied Physiology, 119(11), 1347-1354.

Chaffin, Morgan E., Berg, Kris E., Meendering, Jessica R., Llewellyn, Tamra L., French, Jeffrey A., and Davis, Jeremy E. 2011. Interleukin-6 and Delayed Onset Muscle Soreness Do Not Vary During the Menstrual Cycle. Research Quarterly for Exercise and Sport Vol. 82, No. 4, pp. 693-701

Choy, E., \& Rose-John, S. 2017. Interleukin-6 as a multifunctional regulator: Inflammation, immune response, and fibrosis. Journal of Scleroderma and Related Disorders, 2(Suppl 2), S1-S5.

Cornish, S. M., \& Johnson, S. T. 2014. Systemic cytokine response to three bouts of eccentric exercise. Results in Immunology, 4(1), 2329.

Feraco, A., Gorini, S., Armani, A., Camajani, E., Rizzo, M., \& Caprio, M. 2021. Exploring the role of skeletal muscle in insulin resistance: lessons from cultured cells to animal models. International Journal of Molecular Sciences, 22(17), 1-18.

Glund, S., Desmukh, A., Long, Y.C., Moller, T., Koistinen, H.K., Caidahl, K., Zierath, J.R., Krook, A. 2007. Original Article: 
Interleukin-6 Directly Increases Glucose Metabolism in Resting Human Skeletal Muscle. Diabetes Journals

Hennigar, S. R., McClung, J. P., \& Pasiakos, S. M. 2017. Nutritional interventions and the IL-6 response to exercise. FASEB Journal, 31(9), 3719-3728.

Huldani, Pattelongi, I., Massi, M. N., Idris, I., Bukhari, A., Widodo, A. D. W., Uinarni, H., Carmelita, A. B., Trisia, A., Gunma, S., Prayudhistya, B. K. A., \& Achmad, H. 2020. Cortisol, IL-6, TNF Alfa, Leukocytes and DAMP on Exercise. Systematic Reviews in Pharmacy, 11(6), 474-485.

Lehrskov, L.L., Christensen, R.H. 2019. The Role of Interleukin-6 in Glucose Homeostatis and Lipid Metabolism. Seminars in Immunopathology. 41, 491-499

Morettini, M., Palumbo, M. C., Sacchetti, M., Castiglione, F., \& Mazzà, C. 2017. A system model of the effects of exercise on plasma Interleukin-6 dynamics in healthy individuals: Role of skeletal muscle and adipose tissue. PLoS ONE, 12(7), 1-12.

Pereira, Daniele S., Cipriano, Viviane F., Amorim, Juleimar S. C., Queiroz, Bárbara Z., Felício, Diogo C., Pereira, Leani S. M. 2015. Handgrip strength, functionality and plasma levels of IL-6 in elderly women. Fisioter Mov, 28(3):477-83

Pratiwi, W. N., Purwanto, B., \& Abdurachman. 2019. Diabetes dance of persadia 1 effect on blood IL-6 level. Journal of Physics: Conference Series, 1146(1), 6-11.

Scheller, J., Chalaris, A., Schmidt-Arras, D., \& Rose-John, S. 2011. The pro- and anti-inflammatory properties of the cytokine interleukin-6. Biochimica et Biophysica Acta - Molecular Cell Research, 1813(5), 878-888.

Soares, V., de Avelar, I. S., Venâncio, P. E. M., Pires-Oliveira, D. A. A., Silva, P. H. de A., Borges, A. R., Fonseca, G. P. E. F., \& Noll, M. 2020. Acute changes in interleukin-6 level during four days of long-distance walking. Journal of Inflammation Research, 13(November), 871-878.

Suzuki K. 2019. Characterization of Exercise-Induced Cytokine Release, the Impacts on the Body, the Mechanisms and Modulations. Int J Sports Exerc Med 5:122 